\title{
Bản đồ COVID-19 Việt Nam và thư của TBT Nature
}

Hồ Mạnh Toàn

Phenikaa Uni SDAG Lab (21-3-2020; URL: https://isr.phenikaauni.edu.vn/chitiet/su-kien_2019_2_22_7_59_334/ban-do-covid-19-viet-nam-vathu-cua-nature) - Những ngày cả nước chung tay chống dịch COVID-19 cũng là lúc SDAG Lab tiến hành nghiên cứu xã hội về thông tin và phản ứng chính sách trước đại dịch.

Trong quá trình làm, bản đồ mật độ dịch đã được sản xuất để phục vụ công việc. Bản đồ này được giới thiệu với cộng đồng trong nước và quốc tế, và nhận được sự hoan nghênh, chia sẻ lại (trên Twitter). 


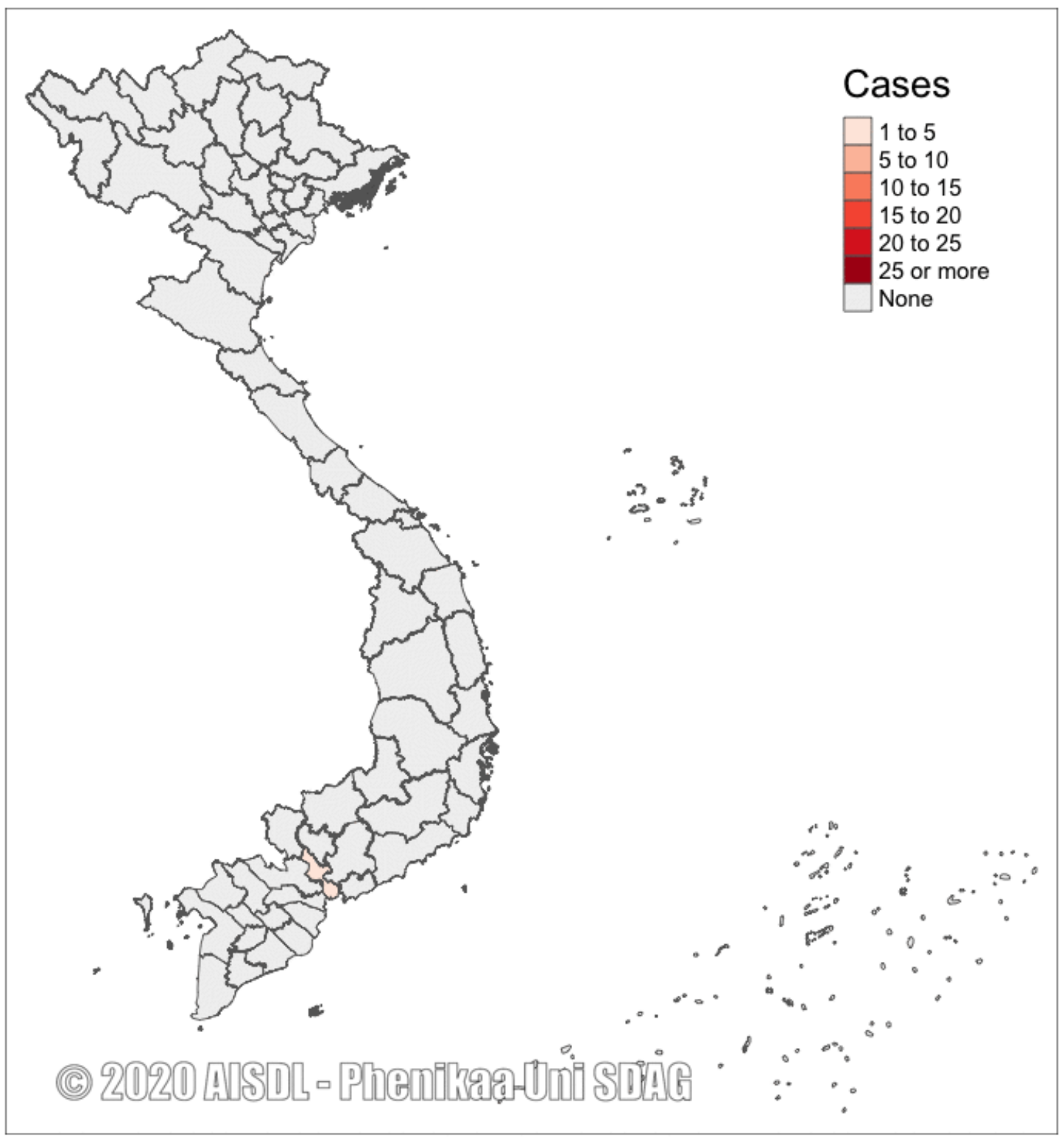

(Phiên bản hình động tại: https://isr.phenikaa-uni.edu.vn/chitiet/sukien_2019_2_22_7_59_334/ban-do-covid-19-viet-nam-va-thu-cua-nature)

Nói thêm về nghiên cứu COVID-19 nói trên, có tiêu đều:

"Policy response, social media and science journalism for the sustainability of the public health system amid COVID-19 outbreak: The Vietnam lessons." [1]

Nó được thực hiện với tinh thần khoa học cao đẹp nhằm chia sẻ thông tin với cộng đồng khoa học và chính sách thế giới, trong cuộc chiến chống COVID-19, hưởng ứng lời kêu gọi của cộng $\mathrm{KH}$ quốc tế (bao gồm cả Nature, Science và $\mathrm{WHO}$ ). Bản thảo nghiên cứu hoàn toàn không nhằm tới việc chỉ để có một công bố quốc tế (cho dù đó là bước tự nhiên tiếp theo). Vì thế, SDAG ISR đã mau 
chóng đưa lên Preprint Servers quen thuộc của thế giới SocArXiv và tới đây là IDEAS/RePEc (qua cổng Université Libre de Bruxelles).

Ngày 20-3, Tổng Biên Tập tạp chí lừng danh 151 tuổi, Nature, đã gửi thư cho GĐ ISR đánh giá cao và hoan nghênh đóng góp của nhóm nghiên cứu. Bà nói:

"Đối sánh và chia sẻ thông tin vô cùng quan trọng ở thời kỳ khủng hoảng chưa từng có tiền lệ này, ngay trong thời đại của chúng ta."

Hiện manuscript này đã được cập nhật lên v.2, và sẽ còn tiếp tục được hoàn thiện. Trong lúc này, nghiên cứu đã bắt đầu nhận được sự quan tâm và nhiều lượt download.

Download: https://osf.io/preprints/socarxiv/cfw8x/download

ISR SDAG hân hạnh được chung tay với thế giới trong công cuộc bảo vệ sức khỏe loài người, với sức vóc khiêm tốn của mình, góp phần làm giảm bớt tổn thất và tăng thêm giá trị của đầu tư khoa học [2].

\section{Tài liệu tham khảo:}

[1] La VP, Pham TH, Ho TM, ..., Vuong QH. (2020). Policy response, social media and science journalism for the sustainability of the public health system amid COVID-19 outbreak: The Vietnam lessons. SocArXiv Preprints; DOI: 10.31235/osf.io/cfw8x.

[2] Vuong QH. (2018). The (ir)rational consideration of the cost of science in transition economies. Nature Human Behaviour 2(1):5; DOI: 10.1038/s41562017-0281-4. URL: https://www.nature.com/articles/s41562-017-0281-4. 